\title{
Employees' Behaviour in Online Social Networking Websites (SNSs)
}

\author{
W.M.S.S. Warnakula ${ }^{1}$ and B. Manickam \\ Postgraduate Institute of Agriculture \\ University of Peradeniya \\ Sri Lanka
}

\begin{abstract}
The present study was conducted to identify the usage level of online social networking websites (SNSS) of employees, to identify the means of using SNSs by employees for personal and professional development, and to identify measures required to facilitate effective use of SNSs for personal and professional development. An online questionnaire survey was conducted with the participation of 74 employees. Employees visit SNSs from the office (98.9\%), home (59.5\%) and other places (21.6\%). The majority (>60.8\%) visits SNSs during office hours. Facebook (98.6\%) and Hi5 (39.2\%) were the most preferred SNSS. The majority (56.5\%) visited SNSs daily while 43\% spent over 60 min. on SNSs daily. Connecting with peers (47.6\%), colleagues at previously employed places (35.7\%), and external professionals (26\%) were the main professional uses of SNSs. Making and maintaining the connections with college and university friends, and friends with personal interests (78\%) and sharing contents (60\%) were the common personal uses. SNSs are used to engage in collective activities, while $98 \%$ are using SNSs to mitigate work stress. Approximately $76 \%$ of employees are expecting to intensify SNSs use. Fifty eight percent of employees had experienced adverse effects of high SNSs use on their office works. Personal use of SNSs is relatively higher than the professional use. Organizations need strategies to raise the awareness of effective SNSs uses among employees. Continuous researches are essential to develop evidence based policies and regulations to ensure the effective use of new media, such as SNSs for constructive personal, organizational and social outcomes, minimizing possible drawbacks.
\end{abstract}

Key words: Employees, Personal, Professional, Social networking.

\section{INTRODUCTION}

The online social networking sites ( $S N S S$ ) have become increasingly popular over the past few years. Major SNSs like Facebook, Twitter, Myspace and Linkedin have positioned with millions of users and still growing attracting thousands of new users daily. For instance, Facebook, which is claimed to have over 400 million active users, had opened half a million new profiles in a day during the period of September $15^{\text {th }}$ to November $6^{\text {th }}, 2009$ (Parr, 2009).These indicate the rapid growth of SNSs among internet users.

Boyd and Ellison (2007), define social networking sites based on three criteria as; "SNSs are the web based services that enable users to; (1) construct a public or semi-public profile within a bounded system, (2) articulate a list of other users with whom they share a connection, and (3) view and traverse their list of connections and those made by, others within the system". The networking features in SNS provide an opportunity to extend ones

\footnotetext{
${ }^{1}$ To whom correspondence should be addressed to: wmsri@yahoo.com
} 
personal network by allowing users to socialize virtually creating online presence and connecting with the chosen people with no geographical boundaries. Most of SNSs include the ability to conduct live chats, send messages, upload images, videos, publishing in fora and blogs, start groups and share the digital resources via internet. Currently the uses and potentials of SNSs are far beyond its basic function of keeping connected.

Broadly, the uses of SNSs can be categorized into two categories as personal and professional or business uses. Using SNSs for flirting, entertainment and other personal life related activities are the personal uses of SNSs. Professional use of SNSs occurs, when an individual or an organization uses SNSs for activities such as creating community for client relationships, crowd-sourcing, product/service ideas, viral marketing programs, and creating support community, researching job applicants, researching job openings, as a sales channel, for content distribution, development of an internal or external professional network, and any other professional/work life related uses.

While professional and business uses are broadening the reach of SNSs into the corporate world, many business professionals are doubtful about potential benefits of SNSs (Brodkin, 2010). Therefore, SNS use of employees in different organizations creates many concerns. The major issue is that the SNS addicted employees spent more office hours on SNSs that leads to productivity losses of the organizations. Furthermore, identity thefts, security to IT network threats and additional costs for organizations are the other main issues.

In the absence of proper research based evidence, most of the worries and criticisms on excessive use of SNSs by employees at working place are made on informal observations and/or personal experiences. However, there is growing evidence to support claims that some SNSs can be a powerful professional ally and opportunity to businesses, organizations and employees (Paul Gillin Communications, 2010).

However, new media like SNSs are attracting the researcher's growing interest in SNSs popularized countries, and the government and organizational decisions making and policy preparations related to IT, web and new media are developed on such scientific research findings (Lenhart et al., 2003). As a result, along with other social media, many organizations are effectively using SNSs to enhance employee productivity and organizational growth through different means. Further as users, policy makers, businesses, educators and parents interested in understanding many-to-many communication, it is essential we understand current usage and behaviour and identify potential problems of SNSs, so that they can be addressed (Ofcom Research, 2008).

Thus as an initiation to fill the existing research gap, this study was carried out with the following objectives: To identify the level of SNSs usage of employees, to identify the ways in which employees are using SNSs for personal development and professional development, and to identify measurers required to facilitate effective use of SNSs for personal and professional development overcoming possible drawbacks.

\section{MATERIALS AND METHODS}

The target group of the study was the SNS using employees in different organizations in Sri Lanka. The primary data were collected with a pre-tested online questionnaire survey and qualitative methods such as discussions and chat sessions with the respondents. Secondary 
data were gathered by referring to published and unpublished research articles and web sites. Online survey was developed and hosted in www.creativepresenters.com; an online survey hosting website and an e-mail was circulated among the target group with an invitation to participate in the survey.

The survey was opened for the period of March $01^{\text {st }}-20^{\text {th }}, 2010$ during which 74 respondents had successfully completed the survey. The survey data were analyzed using Statistical Package for Social Sciences (SPSS) and the descriptive statistics tools like mean, percentage and frequency tests were used to analyze the data. Attitudes of the respondents were analyzed using a Likert Scale.

Judgment sampling in which the researchers first selected the sampling frame based on their judgment from a collected list of e-mail addresses was adopted as the sampling technique for the online survey. Only SNS using employees were included in the sample frame. The main intention of this research was to explore the relevant issues and lay the groundwork for future research on SNSs in Sri Lanka. This is considered as an exploratory study, which introduces the issues and facts and will need to be supplemented with ongoing research. Furthermore, the possibility of generalizing the results of this study to a larger population of employees needs to be considered since the survey sampling did not employ a probability sampling technique.

\section{RESULTS AND DISCUSSION}

\section{Demographic information of respondents}

The surveyed sample of employees had $56 \%$ male $44 \%$ female representation. Most of respondents $(98.7 \%)$ belonged to the age category of $25-35$ years. The major functional areas of the respondent employees at the work places were general management $(19.0 \%)$, sales and marketing $(19.0 \%)$, administration $(14.3 \%)$, production $(14.3 \%)$, human resource management $(9.5 \%)$, customer care $(9.5 \%)$ and academic/teaching $(9.5 \%)$. The largest percentage of respondents were at the executive level $(43.7 \%)$ and $24.4 \%$ were at the management or above the management level. Others were included to the categories such as coordinators $(13.5 \%)$, academic professionals $(9.5 \%)$, and researchers $(5.4 \%)$.

\section{Commonly used social networking websites}

Facebook was the top choice, accounting for $98.6 \%$ of the respondents and $39.2 \%$ had registered profiles in Hi5 (Fig. 1). Only 5.4\% of respondents had profiles in Linkedin, which is solely dedicated for business and professional connections. Meanwhile $58.1 \%$ of respondents claimed that they had profiles in two or more SNSs. 


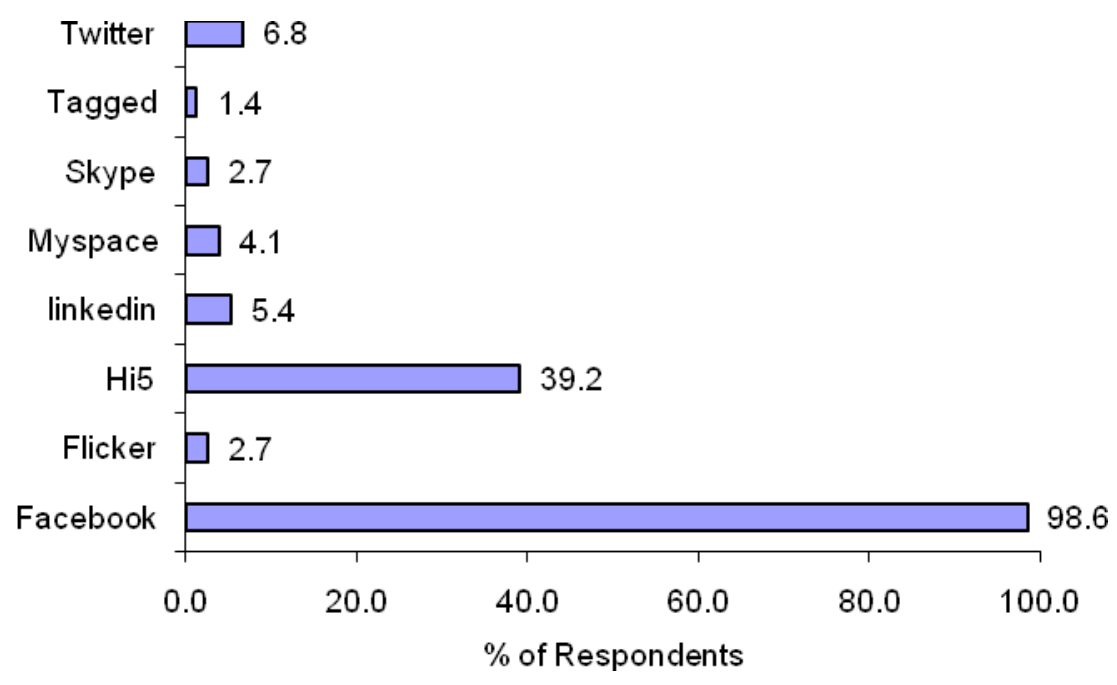

Fig.1. Different SNSs used by respondents

\section{Places of accessing and time spent on SNSs}

Most (98.9\%) accepted that they visited SNSs at office, while 59.5\% of respondents were visiting SNSs at home. In addition, 21.6\% visited SNSs at other places like Internet cafés. The average times spent on SNSs at office, home and other places were 34, 68 and $31 \mathrm{~min}$. respectively. The average total time spent at different locations was 77 min. per day. Nearly $50 \%$ spent 16-60 min. per day on SNSs at office (Table 1). When considering the total time spent at different locations, $43 \%$ of respondents spent more than $60 \mathrm{~min}$. on SNSs per day (Fig. 2).

Table 1. Time spent on SNSs at different places

\begin{tabular}{llll}
\hline \multirow{2}{*}{$\begin{array}{l}\text { Time spent } \\
\text { min) }\end{array}$} & \multicolumn{2}{c}{ Percent respondents } \\
\cline { 2 - 4 } & Office & Home & Other places \\
\hline $1-15$ & 16.2 & 9.5 & 8.1 \\
$16-30$ & 24.3 & 10.8 & 2.7 \\
$31-45$ & 5.4 & 6.8 & \\
$46-60$ & 20.3 & 16.2 & 6.8 \\
$>60$ & 2.7 & 16.2 & 4.1 \\
Non-users & 31.1 & 40.5 & 78.4 \\
Total & 100.0 & 100 & 100 \\
\hline
\end{tabular}




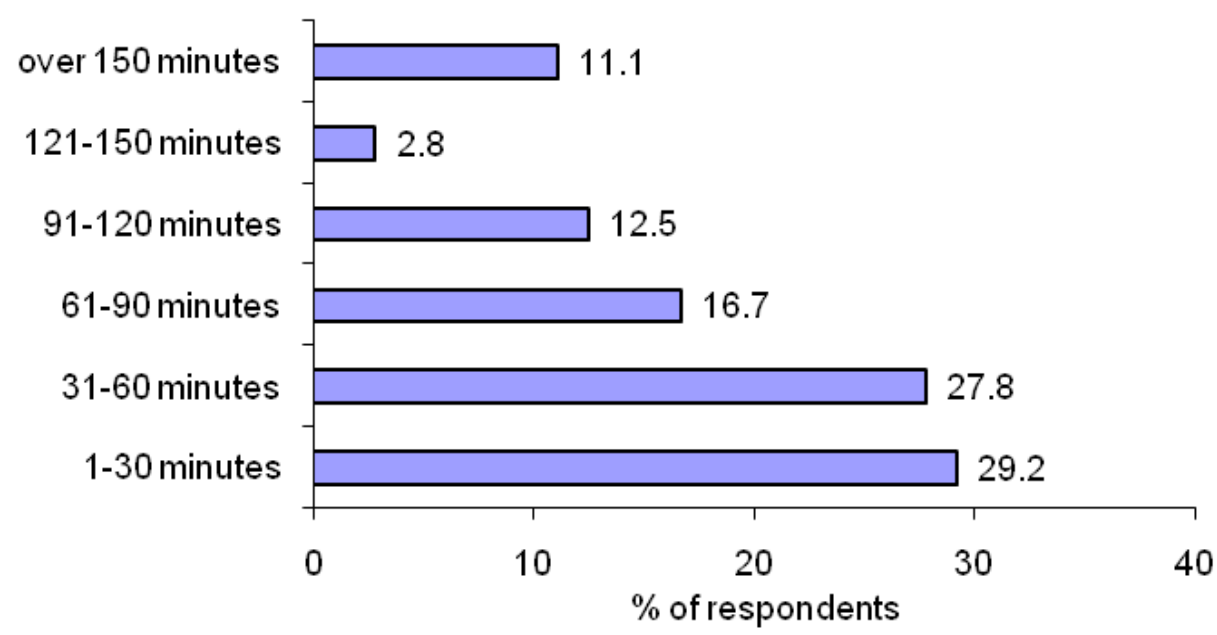

Fig. 2. Total time spent on SNSs daily by respondents

\section{Relative time spent for different activities in SNSs}

As shown in Fig. 3, many users spent the longest period for the activities such as chatting with friends, checking messages and replying to them ( $21.5 \%$ of total time on average). However, only $10.3 \%$ of the total time was spent for reading and/or writing the articles in different forums in SNSs. These fora and their posting could be rich in valuable information on different disciplines. Therefore, if employees spent more time on such activities it would enhance the potential of using SNSs for employees' personal and/or professional development.

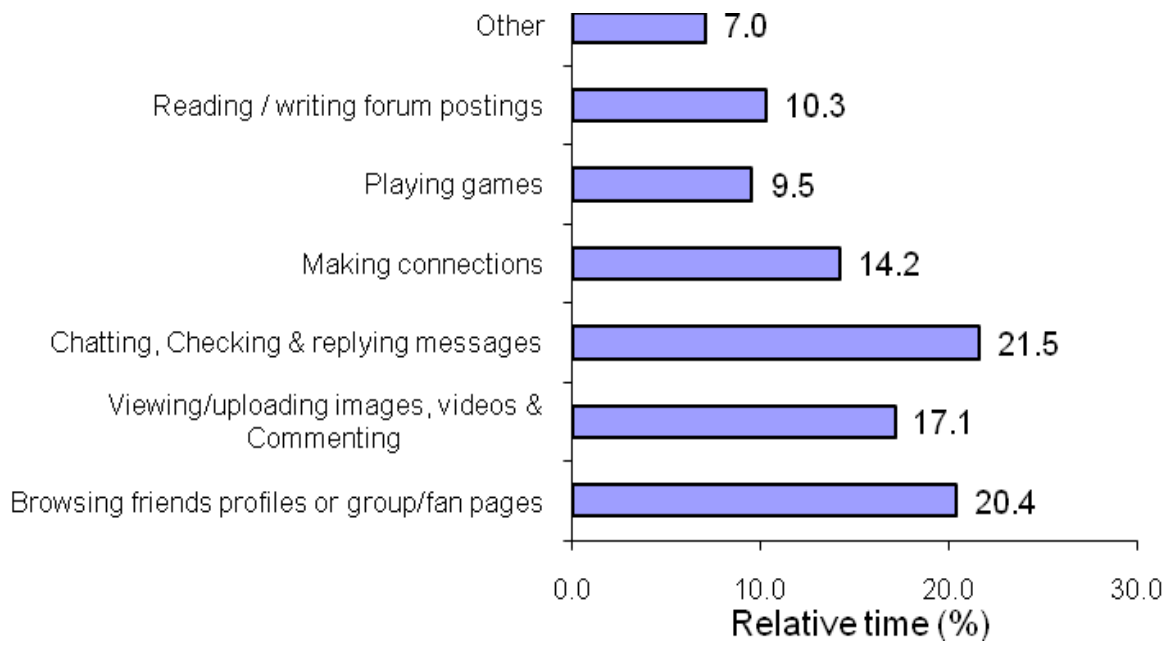

Fig. 3. Relative time spent for different activities on SNSs 


\section{Frequency of visiting SNSs}

Frequency of visiting SNSs is a good indicator of SNSs intensity of the users. Out of the total sample, $57.5 \%$ of the respondents visited SNSs daily and $45.2 \%$ of respondent's $\log$ in to SNSs several times every day (Fig. 4).

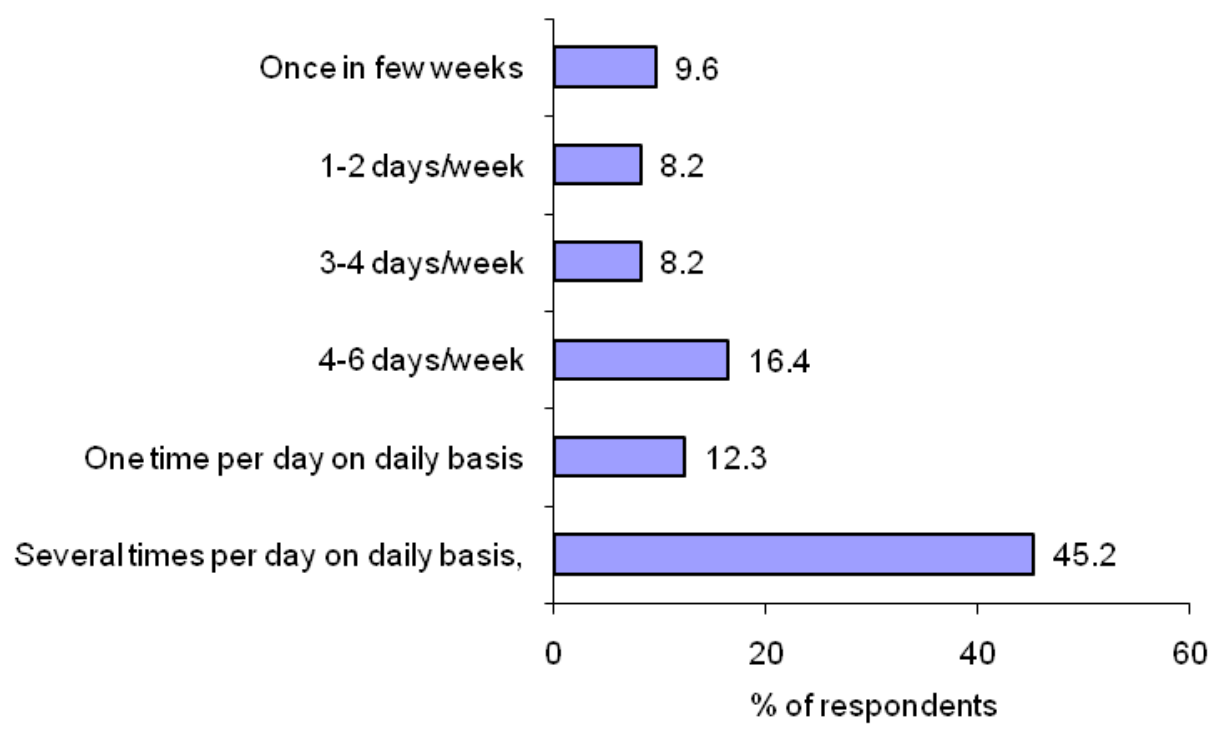

Fig. 4. Frequency of visiting SNSs

\section{Login behaviour and pattern of using SNSs}

As shown in Table 2, 43.2\% of employees visit their usual SNS in the morning at office. Many employees showed a controversial SNSs use behaviour, which could reinforce the concerns of SNSs use and employees' productivity losses.

Table 2. SNSs login behaviour and pattern of use among employees

\begin{tabular}{lll}
\hline Login behaviour & Frequency & Percentage \\
\hline $\begin{array}{l}\text { Log into the site in the morning at office, do some activity } \\
\text { and log out and visit again during free time }\end{array}$ & 18 & 24.3 \\
$\begin{array}{l}\text { Log into the site in the morning at office, and while logged } \\
\text { in keep on doing my office work }\end{array}$ & 14 & 18.9 \\
$\begin{array}{l}\text { Log-into site the only after finishing my office work, but } \\
\text { during office hours }\end{array}$ & 13 & 17.6 \\
$\begin{array}{l}\text { Log-into site only after office hours before leaving the } \\
\text { office }\end{array}$ & 3 & 4.1 \\
$\begin{array}{l}\text { Log-into site only from my home, Internet cafe or other } \\
\text { places }\end{array}$ & 22 & 21 \\
NR & & \\
Total & 4 & 5.5 \\
\hline
\end{tabular}




\section{Friends in SNS profile/s}

According to the survey finding, $36.6 \%$ of the respondents had over 150 friends in their SNS profile/s (Fig. 5). The largest category (53\%) of friends is the college and university friends and/or other relatives who are employed at external firms. Importantly, there were $9 \%$ of friends who had been identified after starting the working life of the respondents, but employed at other organizations. Most likely, this category may represent a significant segment in employees' external professional network.

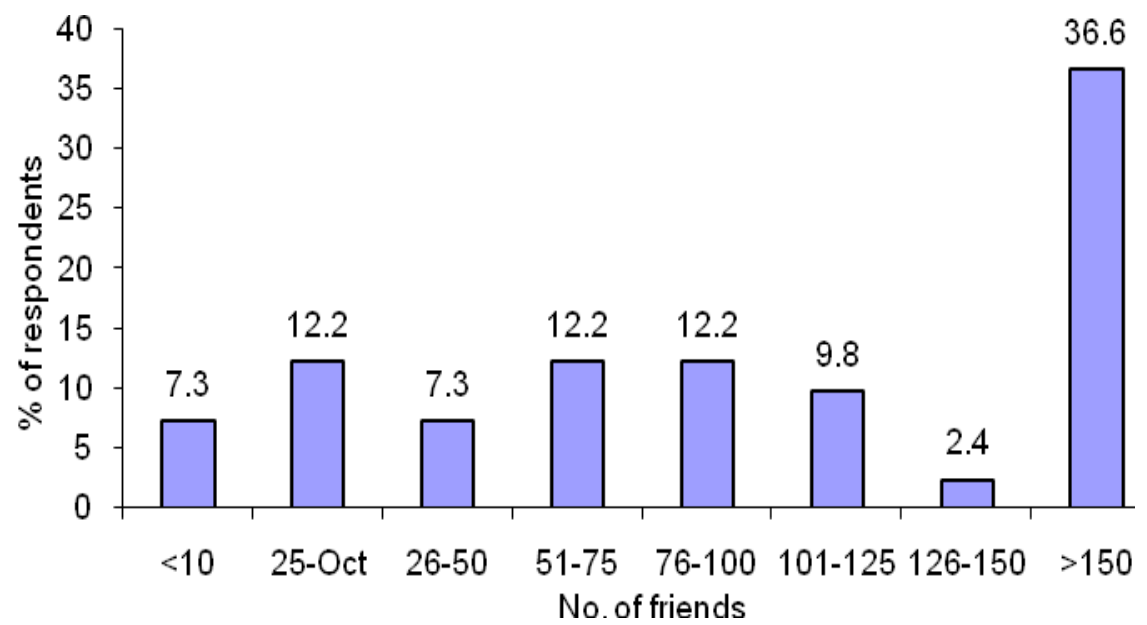

Fig. 5. Number of total friends in SNS profile/s of employees

\section{Professional/work life related uses of SNSs}

The responses for the use of SNSs for different professional/work related activities, which would lead to professional development of the employees, are shown in Table 3. Making connections with the peers at current working place was the most common work related activity (47.6\%). In addition, 36.7\% of respondents had used to keep connections with colleagues at previously employed places. This suggests that SNSs can also have an effect both on the maintained social capital and the bridging social capital of employees.

During discussions it was identified that many users used SNS profile to showcase the various skills they possess and to publish and share the important achievements and milestone in their career. Some had used SNSs to acquire new knowledge through the different groups and forums available in SNSs. In addition, as shown in Fig. 6, many have used SNSs as a communication channel for organized company event/s. Besides the success of respective events, these types of group activities in SNSs may facilitate the development of stronger relationships among company employees and ultimately make the individual employee's life easier. 
Table 3. Professional /work life related uses of SNSs

\begin{tabular}{ll}
\hline Use & \% Respondents \\
\hline Make connections with peers at working place & 47.6 \\
Make connections to colleagues at previously employed places & 35.7 \\
Stay connected with professionals from external organizations & 26 \\
Searching for new jobs and/or potential employees & 21.5 \\
To ask questions about things related to work and get answers & 19 \\
Make connections with superiors at working place & 19 \\
Branding/promoting your company & 19 \\
Branding/promoting my self & 16.7 \\
Learn new skills related to my current job & 16.7 \\
Learn new skills related to my future career plans & 14.3 \\
Make connections to employees bellow your level at working place & 14 \\
Make new business or professional contacts & 7.1 \\
Make contacts with customers/ suppliers & 4.8 \\
To post the available job opportunities at work place & 4.8 \\
\hline
\end{tabular}

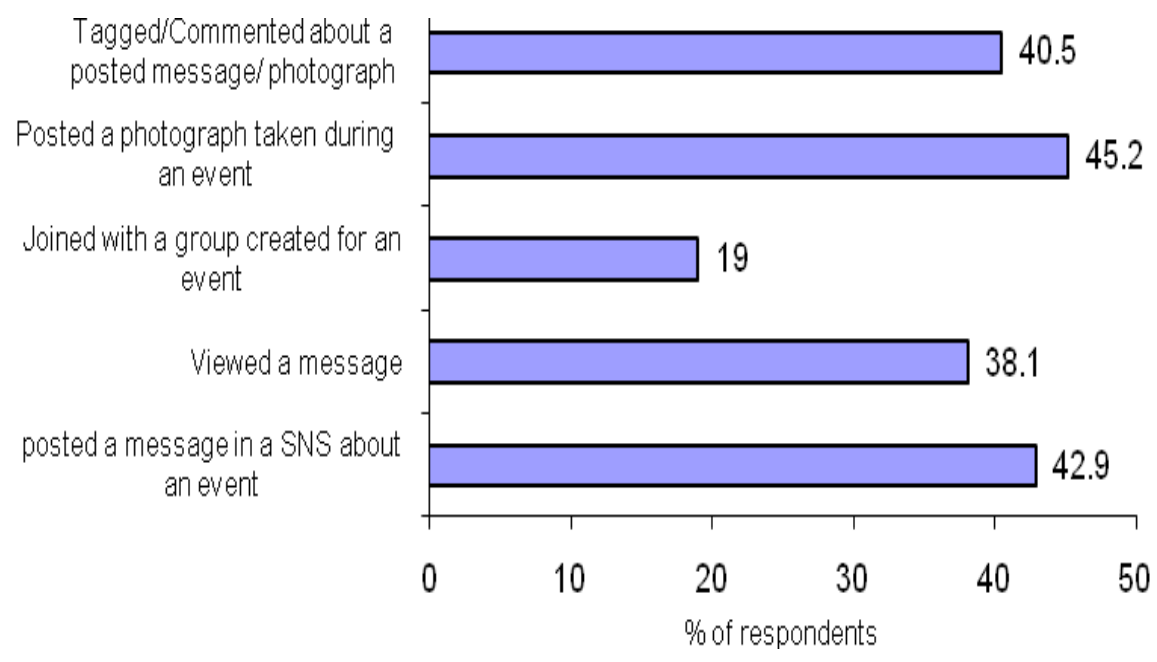

Fig. 6. Use of SNSs to organize company events by employees

The majority (73.8\%) of employees admitted that they discussed the office and work related matters on SNSs with friends; either from internal or external network. As shown in Fig. 7, hardships and problems at work place were the main topics of discussions taken place on SNSs $(40.5 \%)$ at the professional level. There was no evidence to judge the extent and effect of these discussions on employees or organizations. However, if these discussions happened among the internal employees it could help them to mutually understand the concerned issues better and take more productive decisions and actions. 


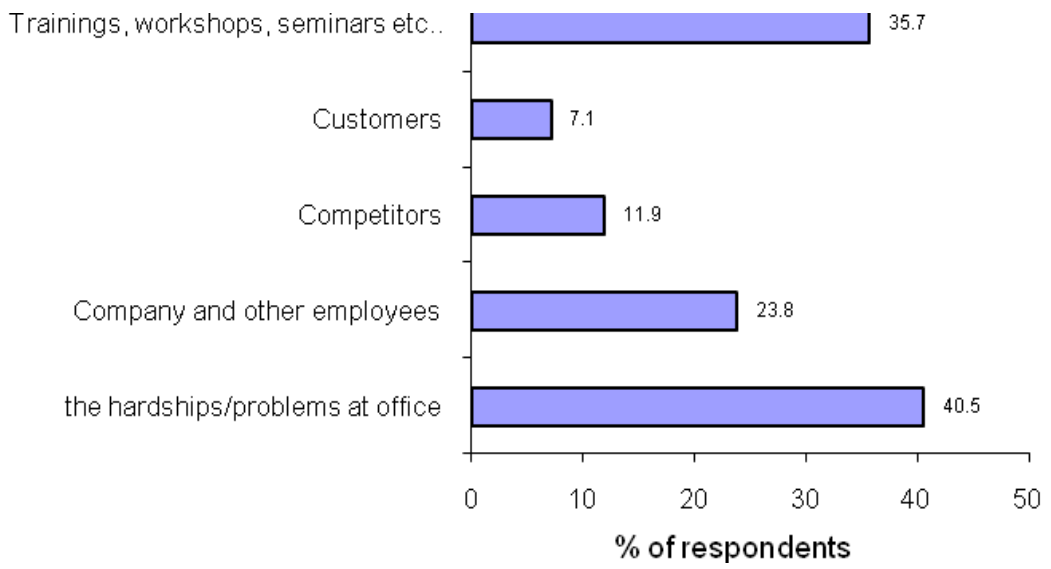

Fig. 7. Topics of discussions taking place in SNSs

\section{Negative effects of SNSs and responses of organizations}

According to respondent employees' self judgment, the majority admitted that they had experienced sometime $(29 \%)$ or rarely $(29 \%)$, their SNS behaviour had disturbed or adversely affected their professional/work life. The common reason stated for this was the spending of more time than expected when visiting SNSs at work places.

Meanwhile $28 \%$ of respondent employees felt that their employers did not like using SNSs by employees at office. In addition, $26.8 \%$ of the respondents noted that, the working organization had restricted or banned SNSs in their IT networks while 7.3\% of employees are advised not to use SNSs at work place. However, the majority, $65.6 \%$ of employees had the freedom to use SNSs at their work place. Findings in Table 4 suggest that the majority of employees see more opportunities of using SNSs for organizational development, but the employers have not recognized such opportunities. Especially nearly, 1/3 of the respondents believed that communicating via SNSs could be effective in terms of saving time and costs compared to e-mail and telephones. This might be due to the reduction of hassles involved with conventional communication channels, by suggested new method.

Table 4. Employees satisfaction on the level of SNSs use by the employers

\begin{tabular}{lc}
\hline Level of satisfaction & \% Respondents \\
\hline Satisfied & 31 \\
Neutral & 29 \\
Dissatisfied & 5 \\
I do not think SNSs can do anything for my company & 9 \\
Cannot answer & 26 \\
\hline
\end{tabular}




\section{Overall impact of SNSs for professional/work life}

As shown in Fig. 8, 54.8\% of respondents accepted that SNSs have been beneficial to their professional/ work life by any means.

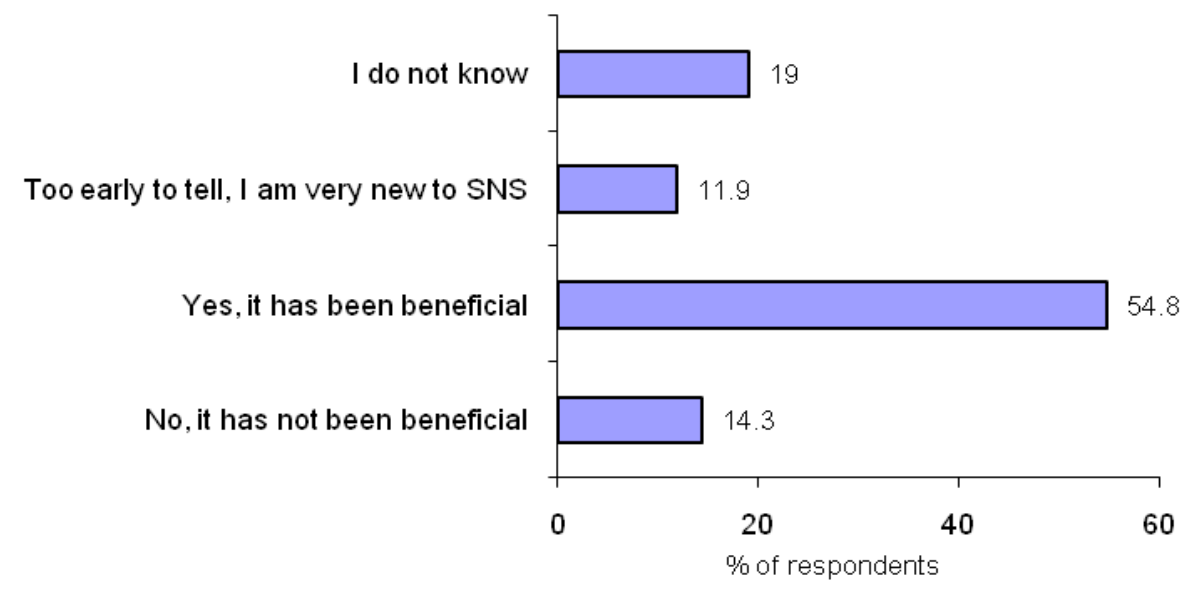

Fig. 8. Overall impact of SNSs on respondent's professional/work life

\section{Personal uses of SNSs}

Staying connected with personal friends especially the college and university friends, and interacting with them via various means (i.e. greetings, photo and video sharing, tagging and commenting on SNS posts etc.) was the primary and frequent personal uses of SNSs (Table 5). When comparing these figurers with Table 3, it is obvious that the intensity of using SNSs for personal relationships is very much higher than the intensity of making and maintaining professional connections.

Table 5. Personal uses of SNSs

\begin{tabular}{ll}
\hline Use & \% Respondents \\
\hline Stay in touch with college/university friends & 78 \\
Send greetings to friends i.e birthday, New Year & 70 \\
Share photos, videos and web links with friends & 60 \\
Tag, comment about your and your friend's posts (status updates, & 60 \\
photos etc.) & 43 \\
Discuss about personal life related matters & 40 \\
Publish and share your achievements in life & 33.5 \\
Get news about current events and educate my self & 30 \\
Make new friends on personal interest & 23.5 \\
Play online games & 23 \\
To build or maintain a romantic relationship with someone & 23 \\
Research about things related to personal life & 17 \\
Brand/Promote yourself among your friends & 17 \\
Ask questions and get answers about things related personal life & 10 \\
Discuss about other companies, products, and services & \\
\hline
\end{tabular}




\section{Membership in groups on SNSs}

Sixty percent of employees had the membership in Alumni groups whereas $47 \%$ had joined professional associations (Fig. 9). In addition, 17\% of employees had received the membership in different technical subject forums on SNSs. Involvement in such groups can be more effective in their professional development.

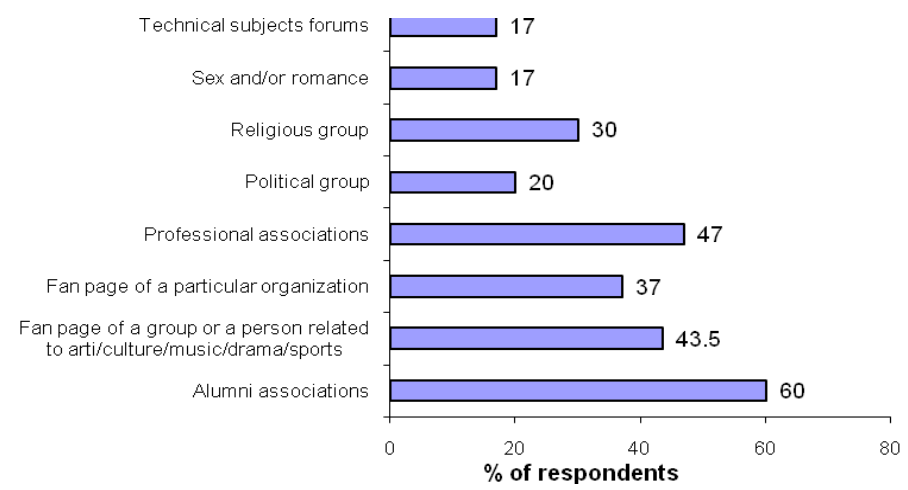

Fig. 9. Memberships in different groups on SNSs

\section{Use of SNSs for emotional rewards}

The emotional rewards that the respondent employees received through SNS engagement were identified as excessively affecting high SNSs intensity among them (Table 6). Reduction of the stress caused by office work was a reason for using SNSs by $98 \%$ of respondent employees. However, $33.3 \%$ of respondents admitted that the sole purpose of their SNSs use is for entertainment.

Table 6. Use of SNSs for emotional rewards

\begin{tabular}{ll}
\hline Statement - SNSs use & \% Respondents \\
\hline Reduce my stress caused by office works & 98 \\
Reduce my stress caused by personnel matters & 63.5 \\
Makes me feel I am connected to a larger community & 77 \\
Make me feel I am valued by others & 70 \\
When I feel lonely, there are several people online I can talk to & 60 \\
\hline
\end{tabular}

In addition, the inputs and suggestions derived through discussions respondents had with friends via SNSs may solve one party's problem/s. Therefore, this may create an online counseling type situation. According to survey data, $43.3 \%$ of respondents had similar experience.

\section{Future changes in employees' SNSs behaviour}

The results shown in Table 7 indicate that despite the existing high SNS intensity among the surveyed employees, it will be further increased shortly. Probably the current level of usage of SNSs for professional /work life related activities will rise simultaneously. 
Table 7. Expected changes in future SNSs behaviour

\begin{tabular}{lllc}
\hline Expected change & \multicolumn{3}{c}{ \% Respondents } \\
\cline { 2 - 5 } & \multicolumn{1}{c}{ Yes } & No & Uncertain \\
\hline I hope to stop/limit my SNSs activity & 10.5 & 62 & 27.5 \\
I do not think I will change current status of my SNSs activity & 14 & 41 & 45 \\
I hope to open a profile in a new SNSs & 20.5 & 41.5 & 38 \\
I need to networking with more professionals in my work area & 72.5 & 3.5 & 24 \\
I need to update my profile with more information & 76 & 7 & 17 \\
I need to add more friends to my profile & 69 & 7 & 24 \\
\hline
\end{tabular}

\section{CONCLUSIONS}

The finding of this study shows that SNS usage is at a very high level among the studied employees. They visit SNSs very frequently from the places such as office (98.9\%), home $(59.5 \%)$ and other places like Internet café $(21.6 \%)$. The majority $(>60.8 \%)$ visit SNSs at office during office hours.

The common professional/work life related uses of SNSs was the making and maintaining the connections with people who can influence the professional life of the employees. Mainly peers at work places (47.6\%), colleagues at previously employed places (35.7\%), and professionals from external organizations $(26 \%)$ were the major constituents of such SNSs based professional networks of the employees. However, the practice of making new business or professional contacts via SNSs was rare (7.1\%). Searching for new jobs and/or potential employees through SNSs was done by approximately $1 / 5^{\text {th }}$ of the employees. Discussing the office matters with SNS friends was common. Sometimes these discussions have been serving as counseling sessions for users, both at a personal level and at professional level. In addition, nearly half of the respondents have used SNSs to communicate about company event to others.

Sometimes the high SNSs use has created negative consequences on 58\% of employees. Although $65.6 \%$ of employees mentioned that they could freely use SNSs at the work place, some organizations have imposed restrictions on SNSs use of employees at work place. Only $31 \%$ of employees are satisfied with the current level of SNSs use by their employers for organizational productivity.

Personal use of SNSs was relatively higher than the professional use among employees. The most common personal uses of SNSs were making and maintaining the connections with college and university friends, and friends with personal interests and sharing the ideas and other personal contents such as photos, videos, web links etc. The uses of SNSs for emotional rewards were common among the employees. The majority $(98 \%)$ of respondents were using SNSs as a means of work place stress mitigation.

Considering the possible future changes in SNS use of the employees, the majority is expecting to update and complete their SNS profile/s and network with more personal friends and professional contacts. Therefore, the immediate interest of organizations in increasing SNS use of employees is needed, in order to direct it in a way that facilitates both organizational growth and professional development of employees. 
Results reflect that many users are limited to the traditional use of SNSs; which is making and maintaining connections with personal friends. However, at professional level, SNSs can be a great way to connect with industry experts, other stakeholders such as customers and suppliers, and for market researches. It can be effectively used of brand an organization or a professional. The potential of integrating the SNSs to facilitate core organizational operations needs to be further explored. Hence, the realization of the full potentials of SNSs will help both employees and employers to use these novel tools more effectively. The organizations could adapt strategies to raise the awareness of such SNS uses among its employees.

A pool of rich information could help decision makers to make fact/evidence based decisions that enable use of new media such as SNSs for effective personal, organizational and social outcomes minimizing possible drawbacks. Thus, the future researches are essential to develop more literature on this area.

\section{REFERENCES}

Boyd, D. M. and Ellison, N.B. (2007). Social network sites: Definition, history, and scholarship [on line]. [Accessed on 12.03.2010]. Available at http://jcmc.indiana.edu/vol13/issue1/ boyd.ellison.html

Brodkin, J. (2010). Facebook, Twitter becoming business tools, but CIOs remain wary [on line]. [Accessed on 10.02.2010]. Available at http://forums.macworld.com/index.php?/topic/ $\underline{121437-1}$

Lenhart, A., Purcell, K., Smith, A. and Zickuhr, K. (2003). Social Media \& Mobile Internet Use among Teens and Young Adults. Washington, D.C., Pew Internet \& American Life Project [on line]. [Accessed on 10.03.2010]. Available at

www.pewinternet.org/Reports/.../Social-Media-and-Young-Adults.aspx

Parr, B. (2009). Facebook Adding Half a Million New Users Every Day [on line]. [Accessed on 16.02.2010]. Available at http://mashable.com/2009/11/06/facebook-325-million-users/

Paul Gillin Communications. Social Marketing Goes Multiplatform, Preliminary Report of Ongoing Research [on line]. [Accessed on 28/02/2010]. Available at www.slideshare.net/ pgillin/social-media-goes-multiplatform

Social Networking, A quantitative and qualitative research report into attitudes, behaviours and use by Ofcom. (2008). [on line]. [accessed on 22.02.2010]. Available at www.ofcom.org.uk 